\title{
Acute Renal Failure during Progressive Systemic Sclerosis in the Regional University Teaching Hospital of Brest-La Cavale Blanche (France)
}

\author{
Comlan Albert Dovonou ${ }^{1}$, Cossi Adébayo Alassani ${ }^{*}$, Séraphin Ahoui ${ }^{1}$, Lauren Gueguen², \\ Arthur Capdeville², Elie Cornec-Le Gall2 ${ }^{2}$, Laurent Doucet ${ }^{2}$, Yannick Le Meur ${ }^{2}$ \\ ${ }^{1}$ Borgou Regional University Teaching Hospital, Parakou, Benin \\ ${ }^{2}$ Regional University Teaching Hospital of Brest-La Cavale Blanche, Brest, France \\ Email: *adebayoalassani@gmail.com
}

How to cite this paper: Dovonou, C.A., Alassani, C.A., Ahoui, S., Gueguen, L., Capdeville, A., Gall, E.C.-L., Doucet, L. and Meur, Y.L. (2017) Acute Renal Failure during Progressive Systemic Sclerosis in the Regional University Teaching Hospital of Brest-La Cavale Blanche (France). Open Journal of Rheumatology and Autoimmune Diseases, 7, 158-166.

https://doi.org/10.4236/ojra.2017.73016

Received: June 21, 2017

Accepted: August 15, 2017

Published: August 18, 2017

Copyright ( $) 2017$ by authors and Scientific Research Publishing Inc. This work is licensed under the Creative Commons Attribution International License (CC BY 4.0).

http://creativecommons.org/licenses/by/4.0/

\begin{abstract}
Systemic scleroderma is a rare disease in which visceral manifestations occur, particularly peripheral vascular, digestive, cardiopulmonary and renal. It is pathology with a predilection for women. The present clinical case is that of a man with the renal complications of scleroderma and the difficulties of the treatment even in the developed countries like France. In the present case, the management of this disease required a high dose of corticosteroid therapy and extra-renal purification. Early detection of complications through a minimal clinical examination supplemented with paraclinic tests has proved necessary.
\end{abstract}

\section{Keywords}

Systemic Sclerosis, Acute Renal Failure, Brest, France

\section{Introduction}

Progressive systemic sclerosis is a rare disease during which visceral manifestations occur, in particular vascular peripheral, digestive, cardiopulmonary and renal ones [1] [2].

It is characterized by microcirculation abnormalities and scleroderma and/or visceral sclerosis.

Progressive systemic sclerosis predominantly affects women (3 to 8 women vs. $1 \mathrm{man})$. Peak frequency is between 45 and 64 years. The prevalence of scleroderma is still not well understood; it is estimated at more than 200 million inha- 
bitants in the United States and Oceania, and at 20 to 80 million inhabitants in Asia. In France, this prevalence is 158 million inhabitants [1].

One of the fearsome complications of progressive systemic sclerosis is organic acute renal failure which is rapidly progressive; it is also known as renal crisis. It is characterized by its rapid onset with malignant hypertension and mild proteinuria most often on the occasion of a heart failure [3] [4].

Its occurrence is life-threatening for the patients and reduces patients' survival with progressive systemic sclerosis; it requires a quick management in the hemodialysis unit. Its concurrent progression with an interstitial pneumonia and occurrence of pulmonary arterial hypertension increases mortality rate between $12 \%$ and $14 \%$. Until now, no treatment has proved to be effective on survival. But there is still hope; non-drug therapies like physical rehabilitation are under assessment [5].

The objective of this presentation is to guide any practitioner towards diagnosis of renal crisis in the face of sudden multiple organ failure resulting from progressive systemic sclerosis.

\section{Case Report}

\subsection{Mr. MG Aged 54 Years}

He was admitted to the surgical intensive care unit of the CHRU La Cavale Blanche of Brest on 12 September, 2015 for decompensated diabetic ketoacidosis, acute renal failure and hemolytic anemia.

\subsection{History}

- Medical history

- Type 1 Diabetes since the age of 15.

- Hypothyroidism.

- Hypercholesterolemia treated.

- Tumor of free edge of the tongue treated by chemoradiotherapy-in 2014; in remission since December 2014.

- Possible exposure to asbestos, notion of asbestosis on last chest scans carried out.

- Left pleural effusion in 2014 with pachypleuritis which is not specific to anatomic pathology, of lymphocytic appearance.

- Inflammatory right pleural effusion with mesothelial cells in 2015.

- Surgical:

- Appendectomy.

- Allergy: unknown

- Ongoing treatment on admission:

- Prednisone $40 \mathrm{mg}$ in the morning.

- Pravastatin $40 \mathrm{mg}, 1$ tablet every evening.

- Levothyrox $75 \mu \mathrm{g}$ in the morning.

- Sulfarlem 3 tablets/day.

- Levemir and Novorapid insulin. 


\subsection{History of the Disease}

Since May 2015 Mr. MG has been presenting with recurrent pleural effusions and lower extremity edema without initial etiology identified. Corticotherapy was set up on May 20, 2015 with intake of Prednisone $40 \mathrm{mg}$ in the morning. Pleural punctures carried out resulted in inflammatory pleural fluid rich in eosinophils, associated with a biological inflammatory syndrome, in a patient with history of auto-immunity recently discovered.

These are positive antinuclear antibodies, positive anti-SSB and positive antiScl 70 .

The etiology mentioned was progressive systemic sclerosis. No other causes/factors of heart disease or renal failure were mentioned.

On 10 September, 2015 the patient was admitted again to a private clinic for deterioration of the general condition. He presented at that time with an anasarca picture with bilateral pleural effusion, pericardial effusion and strip of ascites, as well as synovitis in both wrists.

\subsection{Skin is Sclerotic}

The biological test finds out an inflammatory syndrome, a non obstructive and rapidly progressive acute renal failure (ultrasound of urinary tract performed) with elevated creatinine of $250 \mu \mathrm{mol} / \mathrm{L}$ on admission for a reference value estimated at $45 \mu \mathrm{mol} / \mathrm{L}$ early in August 2015. Proteinuria is estimated at $1.27 \mathrm{~g} / \mathrm{L}$. Complete blood count showed hemolytic anemia, lactate dehydrogenase (LDH) was estimated at $1100 \mathrm{UI} / \mathrm{L}$ and Haptoglobin has collapsed $(<0.5 \mathrm{~g} / \mathrm{dL})$. There is also an unbalanced hypothyroidism (TSH at 30) which justifies the increase of Levothyroxine from 75 to $100 \mu \mathrm{g} /$ day.

In addition to this picture of non obstructive acute renal failure with glomerular appearance and anasarca picture, there was a decompensation of his diabetes with a major ketoacidosis. Blood-pH was estimated at 7.18. An intravenous insulin therapy was put in place. Therefore, he was transferred to the surgical intensive care unit for further care.

On admission on 12 September, 2015 Mr. MG was confused in time but oriented in the space. A psychomotor retardation was noted and there was no sensorimotor deficit. Mr. MG was eupneic under $2 \mathrm{l} / \mathrm{mn}$ of $\mathrm{O}_{2}$. The vesicular murmur was reduced to the two bases. Hemodynamics was rather stable on the hypertensive side; blood pressure was estimated at $160 / 80 \mathrm{~mm} \mathrm{Hg}$. Heart rate (HR) was 100 pulses/mn.

Heart sounds were regular and breathless. There was no sign of peripheral hypoperfusion. There were peripheral edemas. There were no other signs of right heart failure.

Abdomen was flexible and defenseless; there were hydroaeric sounds.

The patient showed acute renal failure with oliguria, urea at $25.8 \mathrm{mmol} / \mathrm{L}$ and elevated creatinine at $360 \mu \mathrm{mol} / \mathrm{L}$.

$\mathrm{pH}$ was at $7.18, \mathrm{PaCO}_{2}$ at $104 \mathrm{mmHg}$.

There were anemia at $7.5 \mathrm{~g} / \mathrm{dl}$ and blood platelets at $198,000 \mathrm{elts} / \mathrm{mm}^{3}$ (refer- 
ence blood platelets one month before at 600,000 elts $/ \mathrm{mm}^{3}$ ).

Haptoglobin has collapsed; presence of Schizocytes. Coombs test was negative. Initial practical conduct in the unit consists of:

- Insulin therapy INSE within the framework of ketoacidosis.

- Adequate hydratation.

- Hemodynamic and respiratory monitoring.

- Monitoring of renal function.

- Setting up of probabilistic antibiotic therapy with Tazocilline, Vancomycin and Amiklin.

On 13 September, 2015 Mr. MG presented with abrupt desaturation at 70\%, crackling sounds in the two fields on lung auscultation. Facing that acute pulmonary edema, the patient received Lasilix at the dose of $1 \mathrm{mg} / \mathrm{Kg}$, Risordan as a bolus ( $8 \mathrm{mg}$ altogether) and hemofiltration on an emergency basis on heparin therapy to enable quick clinical improvement.

\subsection{Outcome in the Unit}

Mr. MG is dialyzed in the unit since 13 September, 2015.

In this context of acute renal failure associated with arterial hypertension and mechanic hemolytic anemia, a renal ultrasound was performed by eliminating obstruction.

Immunological examination was carried out; it highlighted anti-SSB positive antibodies, anti-ScL70 positive antibodies; in contrast Anti Neutrophil Cytoplasmic Antibody Auto-anticorps (ANCA) are negative.

In his recent history, Mr. MG reports the appearance of Raynaud's syndrome for about one year, the onset of scleroderma with distal predominance and sclerosis of face for approximately two months and gastro-esophageal reflux.

In the face of this picture, the diagnosis of renal failure with thrombotic microangiopathy of hemolytic and atypical uremic category syndrome is raised.

On 15 September, 2015 a puncture or renal biopsy was performed; results are compatible with vascular nephropathy, secondary lesions, malignant hypertension and thrombotic micro-angiopathy (Figures 1-3).

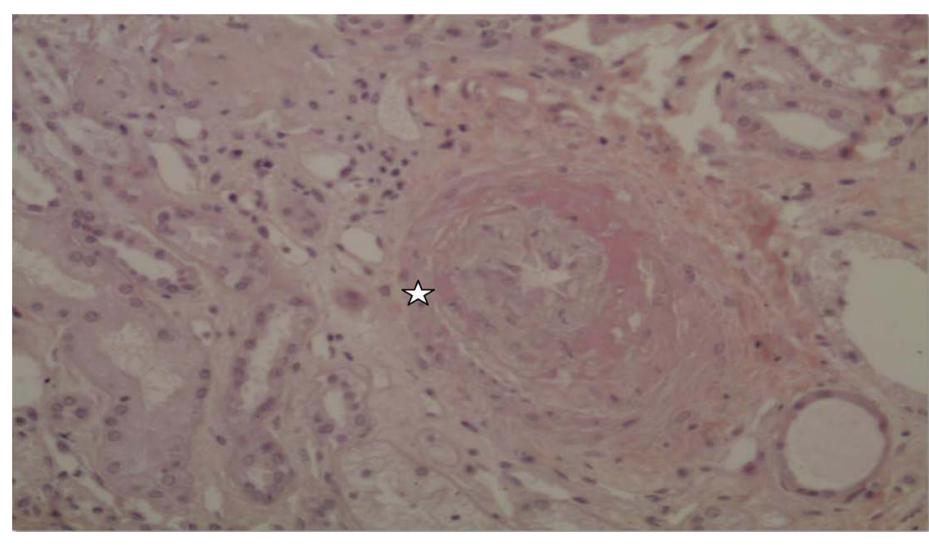

난: Fibrinoid necrosis of an arteriole.

Figure 1. Fibrinoid necrosis of an arteriole. 


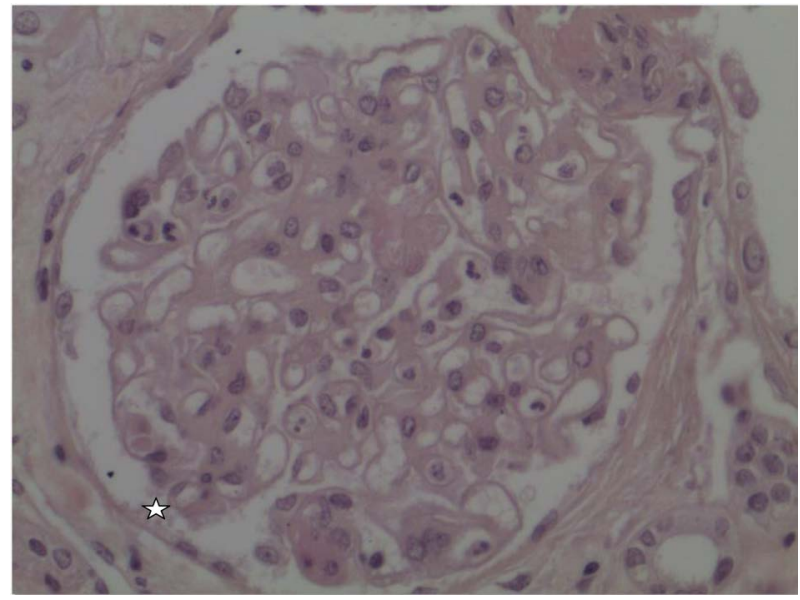

? Glomerulus seat of fibrin microthrombi.

Figure 2. Glomerulus with fibrin microthrombi.

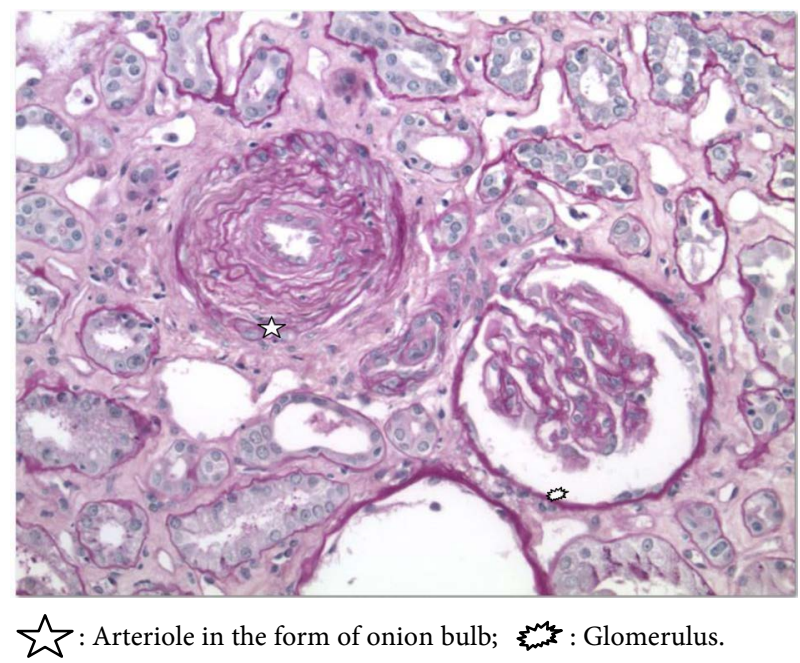

Figure 3. Arteriole in the form of onion bulb.

On 17 September, 2015 the diagnosis of scleroderma renal crisis facilitated by introduction of corticoids at $40 \mathrm{mg}$ /day in that patient carrying progressive systemic sclerosis since May 2015, was retained. Diagnosis was confirmed in the internal medicine unit.

\subsection{Actions Taken}

- Corticotherapy is stopped on 17 September, 2015.

- Setting up of treatment by Angiotensin Converting Enzyme Inhibitor for strict control of blood pressure with an objective lower than 120/60 $\mathrm{mmHg}$.

- Continuation of IV Loxen at $2 \mathrm{mg} / \mathrm{h}$ and Eupressyl $60 \mathrm{mg} \times 2 /$ day, necessary to get a satisfactory blood pressure goal or target. Eupressyl will be increased to $90 \mathrm{mg} \times 2$ /day in order to stabilize blood pressure targets.

- Patient is subject to depletion on average at $2500 \mathrm{ml} / 24$ hours. Besides, there is no associated ionic disorder.

- Facing hypothermia on patient's admission, associated with significant in- 
flammatory syndrome with high procalcitonin level at $9.9 \mathrm{ug} / \mathrm{l}$, a hyperleukocytosis at $40 \mathrm{Giga} / \mathrm{l}$, a triple probabilistic antibiotic therapy with Tazocilline, Vancomycin and Amikacin was put in place; blood cultures performed on the venous-access port are returned positive in two bottles of Staphylococcus epidermidis, peripheral blood cultures are negative. In this context, the venous-access port is withdrawn on 17 September, 2015. The patient will remain apyretic during all the hospitalization period. Triple therapy is stopped on 20 September, 2015.

\subsection{Outcome}

- Systemically: the patient shows Sjögren's syndrome with dry eyes and dry mouth. Scleroderma is predominant in the hands with impossibility of clenching wrists. Hypo-pigmentation signs in the interphalangeal articulations of the two hands and arthralgia affecting wrists are noted.

- At neurological level, the patient is properly oriented in time and space, no sensorimotor deficit was observed.

- As far as respiration is concerned: the patient remained with eupnoea in ambient air. Examination pointed out right pleural effusion syndrome confirmed by ultrasound; it will be evacuated. Puncture fluid is compatible with transsudat; there is no abnormal cell, no germ.

- As regards hemodynamics:

Blood pressure is controlled under Angiotensin Converting Enzyme Inhibitor, Ramipril $2.5 \mathrm{mg} /$ day which will be progressively increased to $10 \mathrm{mg} /$ day and Urapidil $90 \mathrm{mg} \times 2 /$ day.

No sign of peripheral hypoperfusion was observed. Heart auscultation remained normal. Heart ultrasound is performed; it did not reveal pulmonary hypertension.

- At regards digestion:

Abdomen remained flexible, depressible and painless. Mr. MG presented with chronic diarrhea. In the context of hemolytic and uremic syndrome, a search for Shiga toxin is undertaken in the feces and for Escherichia coli $0157 \mathrm{H} 7$; results are negative.

Gastrointestinal endoscopy is done: findings are Stage 0 esophagitis, erythematous gastritis with clear gastric fluid and bulbitis. Duodenum is normal.

Biologically: anemia is persistent, with hemoglobin level at $8.3 \mathrm{~g} / \mathrm{dl}$, blood platelets at $142,000 / \mathrm{mm}^{3}$; presence of schizocytes is on the decline. Haptoglobin is still very low.

Hemoglobin level as at 13 October, 2015 is estimated at $10.1 \mathrm{~g} / \mathrm{dl}$.

- The rest of clinical examination is still normal.

The consent of Mr. MG for the publication of this case was obtained.

\section{Discussion}

The clinical case of Mr. MG raises some reactions. Scleroderma is a rare disease during which visceral manifestations occur, in particular vascular peripheral, 
digestive, cardiopulmonary and renal ones [6] [7]. It is characterized by microcirculation abnormities and lesions in scleroderma and/or visceral sclerosis. Sometimes, those sclerotic lesions may be moderate and distal, involving only fingers, toes and circumference of mouth or sometimes very extended above knees, elbows and even trunk. This disease mainly affects women ( 3 to 8 women vs. 1 man). The age group from 45 to 64 years is the most affected [8] [9].

Its pathophysiology is complex and still not well known, including dysfunctions of endothelial cells, fibroblasts and lymphocytes. The malfunction of fibroblasts is characterized by uncontrolled activation enabling the synthesis of excess extra-cellular matrix. The endothelial cells synthesize excess endothelin-1 which is a powerful vasoconstrictor. Antinuclear antibodies are detectable in the serum of most patients, directed against nuclear proteins or recognizing the endothelial cells and/or fibroblasts. Oxidative stress seems to play a major role in scleroderma pathogenesis [10] [11].

All those abnormalities may be associated with genetic predisposition.

Mr. MG is 54 years old; he has been suffering from scleroderma, polyarthralgia and Raynaud's syndrome for some years. He also has visceral and cardiopulmonary dysfunctions with heart decompensation and bilateral pleuro-pneumopathy complicated by episodes of desaturation. This confirms systemic scleroderma diagnosis.

Scleroderma renal crisis is a complication of systemic scleroderma, abrupt onset with arterial hypertension, grade III or IV hypertensive retinopathy, increased peripheral activity of rennin which may reach twice the normal threshold and rapid deterioration in renal function in one month [10] [12]. Such is the case in Mr. MG whose elevated creatinine increased from $45 \mu \mathrm{mol} / \mathrm{L}$ in early August 2015 to $250 \mu \mathrm{mol} / \mathrm{L}$ on 10 September, 2015 and to $360 \mu \mathrm{mol} / \mathrm{L}$ on 12 September, 2015. Sometimes, this renal crisis may develop with few signs or almost silently. [4]. It is important to identify it; early diagnosis and quick management are the only means of favorable outcome. Renal crisis occurs very quickly after about three years of progression of the initial disease [12].

The immunological examination of this patient confirms the existence of a connective tissue disease (CTD); in this case it is scleroderma. It would have been necessary to measure anti-RNA polymerase III antibodies (Pol3) so as to confirm that diagnosis. Our center does not carry out this examination. In literature, all the authors agree on the specificity of Pol3 in the scleroderma renal crisis [13] [14]. The identification of POLR3A sub-unit which is a mutation of Anti-RNA Polymerase III antibody in a patient is an indication of the concurrent outcome of an underlying cancer. Considering the bundle of clinical, paraclinical and therapeutic arguments, scleroderma renal crisis was retained [15] [16].

As the patient was put on Angiotensin Converting Enzyme Inhibitor and hemodialysis in accordance with literature data, outcome was adequate. In general, remission is complete after 2 years of renal clearance; beyond this length of time, kidney transplantation must be contemplated. Actually, early treatment is a de- 
termining factor for patients' survival and is now the key therapeutic objective during progressive systemic sclerosis [17] [18].

\section{Conclusion}

Progressive systemic sclerosis is a severe form that causes significant reduction of survival of patients with scleroderma. This severity is associated with occurrence during disease progression of visceral disorders, more particularly severe interstitial pneumonia and pulmonary hypertension which may cause death in the patients. Scleroderma renal crisis is a dramatic picture facilitated by introducing in the scleroderma treatment a high dose corticotherapy outcome of which is quickly favorable on Angiotensin Converting Enzyme Inhibitor, and extrarenal excretion after stopping corticoids. The severity of those visceral disorders justifies their systematic and repeated detection through oriented history-taking, clinical examination and further tests.

\section{References}

[1] HAS (High Authority of Health)/Department of Chronic Diseases and Disease Assistance Mechanisms (2015) Chronic Diseases. High Authority of Health, Paris.

[2] Hamaguchi, Y., Kodera, M., Matsushita, T., Hasegawa, M., Inaba, Y. and Usuda, T. (2015) Clinical and Immunologic Predictors of Scleroderma Renal Crisis in Japanese Systemic Sclerosis Patients with Anti-RNA Polymerase III Autoantibodies. Arthritis \& Rheumatology, 67, 1045-1052. https://doi.org/10.1002/art.38994

[3] Woodworth, T.G., Suliman, Y.A., Furst, D.E. and Clements, P. (2016) Scleroderma Renal Crisis and Renal Involvement in Systemic Sclerosis. Nature Reviews Nephrology, 12, 678-691. https://doi.org/10.1038/nrneph.2016.124

[4] Domsic, R.T., Nihtyanova, S.I., Wisniewski, S.R., Fine, M.J., Lucas, M. and Kwoh, C.K. (2016) Derivation and External Validation of a Prediction Rule for Five-Year Mortality in Patients With Early Diffuse Cutaneous Systemic Sclerosis. Arthritis \& Rheumatology, 68, 993-1003. https://doi.org/10.1002/art.39490

[5] Kurts, C., Panzer, U., Anders, H.J. and Rees, A.J. (2013) The Immune System and Kidney Disease: Basic Concepts and Clinical Implications. Nature Reviews Immunology, 13, 738-753. https://doi.org/10.1038/nri3523

[6] Winstone, T.A., Assayag, D., Wilcox, P.G., Dunne, J.V., Hague, C.J. and Leipsic, J. (2014) Predictors of Mortality and Progression in Scleroderma-Associated Interstitial Lung Disease: A Systematic Review. Chest, 146, 422-436. https://doi.org/10.1378/chest.13-2626

[7] Freire, M., Gómez-Sousa, J., Val, N., Baroja, A., Alonso, M., Sousa, A. and Sopeña, B. (2014) SAT0329 Scleroderma in Men in Northwestern Spain: Differentiating Clinical Features. Annals of the Rheumatic Diseases, 73, 711-714. https://doi.org/10.1136/annrheumdis-2014-eular.2014

[8] Pasarikovski, C.R., Granton, J.T., Roos, A.M., Sadeghi, S., Kron, A.T. and Thenganatt, J. (2016) Sex Disparities in Systemic Sclerosis-Associated Pulmonary Arterial Hypertension: A Cohort Study. Arthritis Research \& Therapy, 18, 30-36. https://doi.org/10.1186/s13075-016-0933-1

[9] Shah, A.A., Hummers, L.K., Casciola-Rosen, L., Visvanathan, K., Rosen, A. and Wigley, F.M. (2015) Examination of Autoantibody Status and Clinical Features Associated with Cancer Risk and Cancer-Associated Scleroderma. Arthritis \& 
Rheumatology, 67, 1053-1061. https://doi.org/10.1002/art.39022

[10] Steen, V.D. (2014) Kidney Involvement in Systemic Sclerosis. Medical Press, 43, 305-314. https://doi.org/10.1016/j.lpm.2014.02.031

[11] DeMarco, P.J., Weisman, M.H., Seibold, J.R., Furst, D.E., Wong, W.K., Hurwitz, E.L., et al. (2002) Predictors and Outcomes of Scleroderma Renal Crisis: The HighDose versus Low-Dose D-Penicillamine in Early Diffuse Systemic Sclerosis Trial. Arthritis \& Rheumatology, 46, 2983-2989. https://doi.org/10.1002/art.10589

[12] Nagaraja, V., Denton, C.P. and Khanna, D. (2014) Old Medications and New Targeted Therapies in Systemic Sclerosis. Rheumatology, 54, 1944-1953.

https://doi.org/10.1093/rheumatology/keu285

[13] Esposito, J., Brown, Z., Stevens, W., Sahhar, J. and Rabusa, C. (2016) The Association of Low Complement with Disease Activity in Systemic Sclerosis: A Prospective Cohort Study. Arthritis Research \& Therapy, 18, 246-251. https://doi.org/10.1186/s13075-016-1147-2

[14] Sobanski, V., Dauchet, L., Lefevre, G., Lambert, M., Morell-Dubois, S. and Sy, T. (2014) Prevalence of Anti-RNA Polymerase III Antibodies in Systemic Sclerosis: New Data from a French Cohort and a Systematic Review and Meta-Analysis. Arthritis \& Rheumatology, 66, 407-417.

[15] Montaneli, G., Beretta, L., Santaniello, A. and Scorza, R. (2013) Effect of Dihydropyridine Calcium Channel Blockers and Glucocorticoids on the Prevention and Development of Scleroderma Renal Crisis in an Italian Case Series. Clinical and Experimental Rheumatology, 31, 135-139.

[16] Mehra, S., Walker, J., Patterson, K. and Fritzler, M.J. (2013) Autoantibodies in Systemic Sclerosis. Autoimmunity Reviews, 12, 340-354.

[17] Lynch, B.M., Stern, E.P., Ong, V., Harber, M., Burns, A. and Denton, C.P. (2016) UK Scleroderma Study Group (UKSSG) Guidelines on the Diagnosis and Management of Scleroderma Renal Crisis. Clinical and Experimental Rheumatology, 34, 106-109.

[18] Kowal-Bielecka, O., Fransen, J., Avouac, J., Becker, M., Kulak, A. and Allanore, Y. (2017) Update of EULAR Recommandations for the Treatment of Systemic Sclerosis. Annals of the Rheumatic Diseases, 1-12.

\section{Scientific Research Publishing}

\section{Submit or recommend next manuscript to SCIRP and we will provide best service for you:}

Accepting pre-submission inquiries through Email, Facebook, LinkedIn, Twitter, etc. A wide selection of journals (inclusive of 9 subjects, more than 200 journals) Providing 24-hour high-quality service User-friendly online submission system Fair and swift peer-review system Efficient typesetting and proofreading procedure Display of the result of downloads and visits, as well as the number of cited articles Maximum dissemination of your research work

Submit your manuscript at: http://papersubmission.scirp.org/ Or contact ojra@scirp.org 